\title{
CARRIER DIAGNOSIS BY RFLP ANALYSIS IN A FAMILY AFFECTED WITH INFANTILE HYPOPHOSPHATASIA : CASE REPORT
}

\author{
Atsushi Akane, ${ }^{1}$ Hiroshi Shiono, ${ }^{1}$ Kazuo Matsubara, ${ }^{1}$ \\ Hiroaki Nakamura, ${ }^{1}$ Masanori Hasegawa, ${ }^{1}$ Masato Kagawa, ${ }^{1}$ \\ Ayame Kobayashi, and Chuzo Mori ${ }^{2}$ \\ Departments of ${ }^{1}$ Legal Medicine and ${ }^{2}$ Pediatrics, Shimane Medical University, \\ Izumo 693, Japan
}

\begin{abstract}
Key Words carrier diagnosis, infantile hypophosphatasia (HOPS), liver/bone/kidney alkaline phosphatase (ALPL), restriction fragment length polymorphism (RFLP)
\end{abstract}

Infantile hypophosphatasia (HOPS) is an autosomal recessive disorder, which presents within the first 6 months of life, and is characterized by systemic bone mineralization abnormality with low or deficient activity of serum and tissue alkaline phosphatase (ALP). HOPS carriers, who may also reveal low ALP activity, can be determined by analyses of certain biochemical parameters (Chodirker et al., 1990). Genetically, the HOPS gene is strongly linked to the $\mathrm{Rh}$ blood group locus (RH, 1p36.2-34) (Chodirker et al., 1987) and to the liver/bone/kidney-type ALP (ALPL) locus (1p36.1-34) (Greenberg et al., 1990). The restriction fragment length polymorphism (RFLP) of the ALPL locus found in MspI-digested DNA samples was thus informative for carrier and prenatal diagnoses. In this paper, we also describe RFLP analyses of ALPL and other DNA markers for the assignment of carriers in a family affected with HOPS.

A HOPS patient, who had bony ossification abnormalities, died on the 18th day after birth due to respiratory insufficiency caused by thorax hypoplasia. Although the infant's 2-year-old sister was healthy, the parents' first daughter had also died because of the same disorder, at 15 days after birth, and the mother's second pregnancy had ended in a spontaneous abortion. Blood samples were extracted from the patient, her sister, and the parents. No sample was available from the first child.

Biochemical parameters shown in Table 1 were analyzed at the Central Re-

Received September 9, 1991; revised version received October 3, 1991, Accepted October 21, 1991. 
Table 1. Biochemical parameters and carrier probabilities of the HOPS family.

\begin{tabular}{|c|c|c|c|c|c|c|}
\hline \multirow{2}{*}{ Parameters } & \multirow{2}{*}{\multicolumn{2}{|c|}{$\begin{array}{l}\text { Normal } \\
\text { range }\end{array}$}} & \multicolumn{4}{|c|}{ Determined value } \\
\hline & & & Patient & Father & Mother & Sister \\
\hline \multicolumn{7}{|l|}{ Serum } \\
\hline ALP (IU/liter) & & $73-248$ & 27 & 143 & 89 & 548 \\
\hline $\mathrm{Ca}(\mathrm{mg} / \mathrm{dl})$ & & $8.6-10.3$ & $5.9-10.1$ & 8.7 & 8.6 & 9.0 \\
\hline \multirow[t]{2}{*}{$P_{1}(\mathrm{mg} / \mathrm{dl})$} & adult: & $2.2-4.6$ & & 1.6 & 3.8 & \\
\hline & infant: & $4.5-6.5$ & $6.0-8.7$ & & & 4.6 \\
\hline $\mathrm{PEA}(\mu \mathrm{mol} / \mathrm{dl})$ & & N.D. & 2.3 & 0.9 & 1.2 & 1.0 \\
\hline \multicolumn{7}{|l|}{ Urine } \\
\hline $\mathrm{Ca}(\mathrm{mg} / \mathrm{d} l)$ & & $0.1-0.3(\mathrm{~g} /$ day $)$ & $\cdots$ & 15.5 & 5.2 & 3.1 \\
\hline$P_{i}(\mathrm{mg} / \mathrm{dl})$ & & $0.5-2.0(\mathrm{~g} /$ day $)$ & $\ldots$ & 44 & 33 & 13 \\
\hline PEA (mmol/g creatinine) & & N.D. & 3.1 & N.D. & N.D. & N.D. \\
\hline Carrier probability & & & - & 0.0000001 & 0.7032408 & 0.0000002 \\
\hline
\end{tabular}

N.D., not detected. Normal ranges of urine $\mathrm{Ca}, \mathrm{P}_{\mathrm{i}}$, and $\mathrm{Crea}$ levels are given as total urinary excretions, but only urinary concentrations were examined.

search Laboratories of Shimane Medical University Hospital. The HOPS carrier probabilities for the sister and parents were determined using a diagnostic logistic regression analysis model based on serum ALP and phosphate $\left(\mathbf{P}_{\mathrm{i}}\right)$ levels (Chodirker et al., 1990). Since the normal levels of parameters examined here were different from those used in the model, probably due to different analytical techniques, the determined concentrations were corrected by adjusting the normal ranges for the calculation. Since no phosphoethanolamine (PEA) was excreted in the urine of the subjects, another model based on ALP, $P_{i}$, and urine PEA was omitted for carrier assignment.

The parents in this HOPS family should have been obligate carriers since HOPS is an autosomal recessive disorder. By the former model, the carrier probability of the mother was slightly high 0.7 , according to her low normai ALP activity and normal $\mathrm{P}_{\mathrm{i}}$ level (Table 1). However, the probability of the father was, illogically, too low, because of normal enzyme activity and low $\mathrm{P}_{\mathrm{i}}$ level. Although this diagnostic model had appeared to be quite informative for screening, false positive or negative results have been obtained in a few subjects (Chodirker et al., 1990). This model, which was established in a high-risk HOPS population of Manitoba Mennonite families, might be unsuitable for carrier diagnosis in this family: Since mutations causing HOPS were suggested to be very heterogeneous (Greenberg et al., 1990), the ALP activity of the carriers in this family was possibly less affected than that in the Mennonites. Thus, the result showing the extremelylow probability of the sister being a carrier might be also unreliable. Whether she was a HOPS carrier or not should have been determined by pedigree analysis using polymorphic genetic markers. 
DNA was extracted from peripheral blood leukocytes. Probes used were pS3-1 for the ALPL locus (Weiss et al., 1986), pHU1-1D for the human U1 small nuclear RNA locus (RNU1, Ip36.1) (Lund and Dahlberg, 1984), and pYNZ2 for a variable number of tandem repeat (VNTR) locus (D1S57, 1p) (Nakamura et al., 1987, 1988). These probes were supplied from Japanese Cancer Research Resources Bank and labeled with digoxigenin-11-2'-deoxyuridine-5'-triphosphate (Boehringer Mannheim, Mannheim, Germany) by nick translation for Southern blot analyses. Hybridization signals were detected with anti-digoxigenin-ALP conjugate (Boehringer Mannheim) and visualized by an enzyme-linked color reaction according to the supplier's instruction.

RFLP found within the ALPL locus were analyzed using DNA samples digested by SstI (Ray et al., 1988), BclI (Weiss et al., 1987; Ray et al., 1988), or MspI (Greenberg et al., 1990) (Table 2, Fig. 1). MspI RFLP was monomorphic in this family. Sst I RFLP showed that the patient and her father were homozygous Al/ A1, and that her sister and mother were heterozygous A1/A2. This result indicated that the patient and her sister had inherited different ALPL alleles from their mother. On the other hand, $B c l$ I RFLP revealed that the four were the same heterozygous A1/A2. Since the maternal ALPL alleles of the patient and her sister were different, their paternal alleles were inevitably disparate: When their maternal alleles were assumed to be $\mathrm{A} 1$ and $\mathrm{A} 2$, their paternal alleles would be $\mathrm{A} 2$ and $\mathrm{A} 1$, respectively.

The same result was obtained from RFLP within the RNU1 and D1S57 loci (Table 2). Since the former is located in $1 \mathrm{p} 36.1$, relatively closed linkage might be expected with HOPS. On the other hand, the minute location of the latter locus on chromosome $1 \mathrm{p}$ is unknown. However, because VNTR loci generally exist near the teromeres of chromosomes, and because VNTR markers are highly

Table 2. List of polymorphic markers.

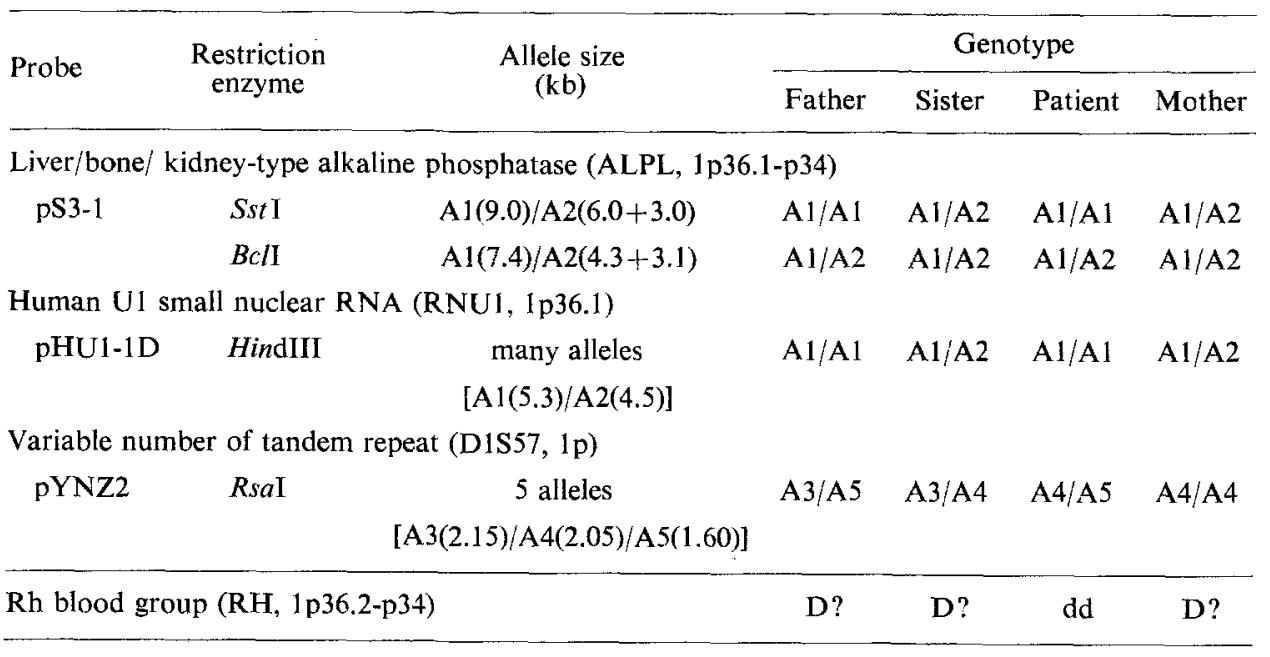



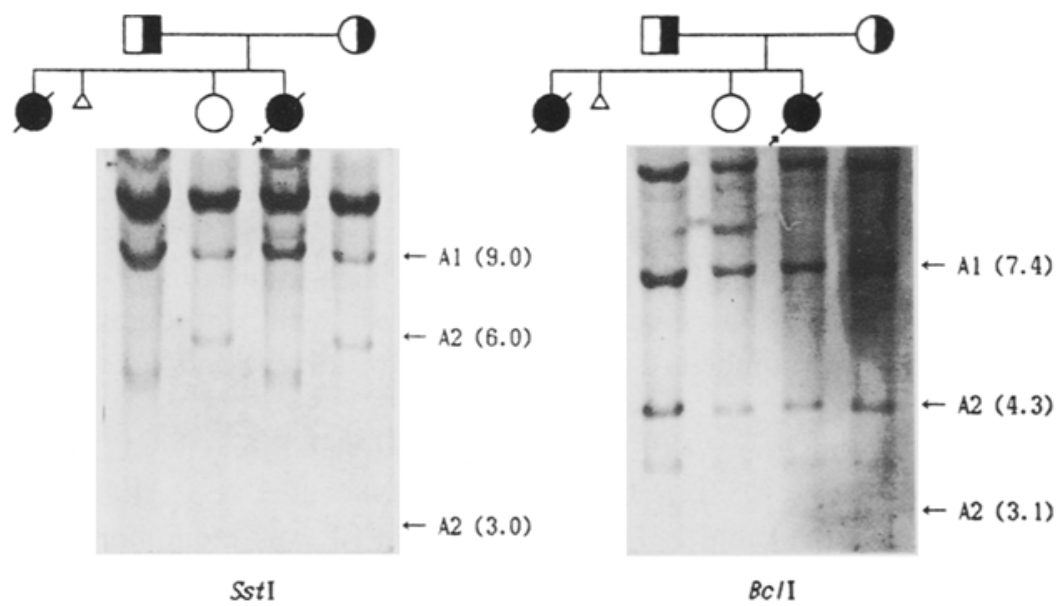

Fig. 1. Sstl (left) and $B c / l$ (right) RFLPs found within ALPL locus in the HOPS family.

informative for pedigree analyses (Akane et al., 1990a, 1990b, 1991), the RFLP was referentially analyzed. Further investigation on the linkages of these markers with the HOPS gene is required.

For $\mathrm{Rh}$ blood grouping, only the $\mathrm{D}$ antigen of the patient had been analyzed while she was still alive. Fortunately, she was homozygous dd while the other members of the family had D antigens (Table 2). According to RFLP, the parents might be heterozygous $\mathrm{Dd}$, and the sister was probably homozygous DD. Thus, the $\mathrm{Rh}^{*} \mathrm{~d}$ allele might segregate with the HOPS gene in this family. However, it would be difficult to assign the HOPS carrier by detection of the d allele in the other blood relatives, because there is no anti-d antisera.

For genetic counseling, it is quite important to assign carriers of such fatal genetic disorders as HOPS. When mutations causing such a disease have not been identified, closely-linked RFLP can be used for diagnosis, as shown in this study. However, RFLP are sometimes not polymorphic in blood relatives. In such cases, the other RFLP should be analyzed. It is thus necessary to establish the minute mapping of RFLP markers on chromosomes.

\section{REFERENCES}

Akane, A., Matsubara, K., Shiono, H., Yuasa, I., Yokota, S.-I., Yamada, M. and Nakagome, Y. 1990a. Paternity testing: blood group systems and DNA analysis by variable number of tandem repeat markers. J. Forensic Sci. 35: 1217-1225.

Akane, A., Nakajima, H., Shiono, H., Matsubara, K., Yamada, M. and Nakagome, Y. $1990 \mathrm{~b}$. A case of maternity testing: exclusion by polymorphic VNTR markers of DNA. $J p n . J$. Human Genet. 35: 319-323.

Akane, A., Matsubara, K., Shiono, H., Yamada, M. and Nakagome, Y. 1991. Diagnosis of twin zygosity by hypervariable RFLP markers. Am. J. Med. Genet. 41: 96-98. 
Chodirker, B.N., Evans, J.A., Lewis, M., Coghlan, G., Belcher, E., Phillipps, S., Seargeant, L.E., Sus, C. and Greenberg, C.R. 1987. Infantile hypophosphatasia-linkage with the RH locus. Genomics 1: 280-282.

Chodirker, B.N., Evans, J.A., Seargeant, L.E., Cheang, M.S. and Greenberg, C.R. 1990. Hyperphosphatemia in infantile hypophosphatasia: implications for carrier diagnosis and screening. Am. J. Hum. Genet. 46: 280-285.

Greenberg, C.R., Evans, J.A., McKendry-Smith, S., Redekopp, S., Haworth, J.C., Mulivor, R. and Chodirker, B.N. 1990. Infantite hypophosphatasia: localization within chromosome region 1p36.1-34 and prenatal diagnosis using linked DNA matkers. Am. J. Hum. Genet. 46: 286-292.

Lund, E. and Dahlberg, J.E. 1984. True genes for human U1 small nuclear RNA, copy number, polymorphism, and methylation. J. Biol. Chem. 259: 2013-2021.

Nakamura, Y., Leppert, M., O'Connel, P., Wolff, R., Holm, T., Culver, M., Martin, C., Fuiimoto, E., Hoff, M., Kumlin, E. and White, R. 1987. Variable number of tandem repeat (VNTR) markers for human gene mapping. Science 235: 1616-1622.

Nakamura, Y., Culver, M., Sergeant, L., Leppert, M., O'Connel, P., Lathrop, G.M., Lalouel, J.-M. and White, R. 1988. Isolation and mapping of a polymorphic DNA sequences (pYNZ2) on chromosome 1p (D1S57). Nucleic Acids Res. 16: 4747.

Ray, K., Weiss, M.J., Dracopoli, N.C. and Harris, H. 1988. Probe 8B/E5' detects a second RFLP at the human liver/bone/kidney alkaline phosphatase (ALPL) locus. Nucleic Acids Res. 16: 2361.

Weiss, M.J., Henthorn, P.S., Lafferty, A., Slaughter, C., Raducha, M. and Harris, H. 1986. Isolation and characterization of a cDNA encoding a human liver/bone/kidney alkaline phosphatase. Proc. Natl. Acad. Sci. U.S.A. 263: 12002-12010.

Weiss, M.J., Spielman, R.S. and Harris, H. 1987. A high frequency RFLP at the human liver/ bone/kidney-type alkaline phosphatase locus. Nucleic Acids Res. 15: 860. 